\title{
Performance modeling of direct contact membrane distillation (DCMD) seawater desalination process using a commercial composite membrane
}

\author{
Jung-Gil Lee ${ }^{\mathrm{a}}$, Young-Deuk Kim ${ }^{\mathrm{b} *}$, Woo-Seung Kim ${ }^{\mathrm{b}}$, Lijo Francis ${ }^{\mathrm{c}}$, Gary Amy ${ }^{\mathrm{c}}$, Noreddine Ghaffour ${ }^{\mathrm{c}}$ \\ ${ }^{a}$ Department of Mechanical Engineering, Hanyang University, 222 Wangsimni-ro, Seongdong-gu, Seoul, \\ Republic of Korea \\ ${ }^{b}$ Department of Mechanical Engineering, Hanyang University, 55 Hanyangdaehak-ro, Sangnok-gu, Ansan, \\ Gyeonggi-do 426-791, Republic of Korea
}

${ }^{c}$ Water Desalination and Reuse Center, King Abdullah University of Science and Technology (KAUST), 239556900 Thuwal, Saudi Arabia

${ }^{*}$ Corresponding author. Tel.: +82 31400 5254; fax: +82 314368146.

E-mail address: youngdeuk@hanyang.ac.kr(Y.-D. Kim).

\begin{abstract}
This paper presents the development of a rigorous theoretical model to predict the transmembrane flux of a flat sheet hydrophobic composite membrane, comprising both an active layer of polytetrafluoroethylene and a scrim-backing support layer of polypropylene, in the direct contact membrane distillation (DCMD) process. An integrated model includes the mass, momentum, species and energy balances for both retentate and permeate flows, coupled with the mass transfer of water vapor through the composite membrane and the heat transfer across the membrane and through the boundary layers adjacent to the membrane surfaces. Experimental results and model predictions for permeate flux and performance ratio are compared and shown to be in good agreement. The permeate flux through the composite layer can be ignored in the consideration of mass transfer pathways at the composite membrane. The effect of the surface porosity and the thickness of active and support layers on the process performance of composite membrane has also been studied. Among these parameters, surface porosity is identified to be the main factor significantly influencing the permeate flux and performance ratio, while the relative influence of the surface porosity on the performance ratio is less than that on flux.
\end{abstract}

Keyword: composite membrane, desalination, direct contact membrane distillation, heat and mass transfer

\section{Introduction}

Membrane distillation (MD) is a thermally-driven membrane separation process. The vapor partial pressure difference, as a driving force of the process, is created by the temperature gradient imposed between the liquidvapor interfaces. Such a MD process has a number of potential advantages, namely, low operating temperature and hydraulic pressure, nearly $99.9 \%$ rejection of non-volatile solutes, low sensitivity to salt concentration, low footprint requirement, performance independent of high osmotic pressure or concentration polarization [1-10] and potentially high permeate flux [11-14]. For such reasons, MD has been considered as an emerging desalination technology for producing fresh water from seawater. However, the MD process has a high conductive heat loss through the membrane, which results in higher energy consumption [1-7]. In this respect, 
much research has been carried out on the various heat recovery concepts to overcome the drawback of MD [1,15-17]. In addition, an ideal polymer membrane applied for MD should possess the following requirements: (i) high permeability with an optimum pore size and porosity, (ii) low thermal conductivity with high thickness and porosity, (iii) high liquid entry pressure of water (LEPw) with high hydrophobicity (i.e., high water contact angle) and small maximum pore size, (iv) high mechanical strength, (v) excellent chemical resistance and (vi) good thermal stability [18]. However, here there exists a conflict between the requirements of an ideal membrane, namely, low conductive heat loss and high mass transfer. It has been known that a relatively simple way to overcome the above conflict is to use a microporous hydrophobic/hydrophilic (or hydrophobic) composite membrane [18].

Since a composite hydrophobic/hydrophilic membrane in MD was patented in the 1980s [19], numerous experimental studies on composite membrane for MD have been reported [18,20-27]. Khayet et al. [18] studied the fluorinated surface-modifying macromolecule (SMM) blended polyetherimide (PEI) membranes for desalination by direct contact membrane distillation (DCMD) and those permeate fluxes were compared with two commercial polytetrafluoroethylene (PTFE) membranes supported by a polypropylene (PP) net. Peng et al. [20] developed a flat sheet composite MD membrane with a hydrophobic PVDF layer on the top of hydrophilic polyvinyl alcohol blended polyethylene glycol (PVA/PEG) sub-layer for desalination by DCMD. Feng et al. [21] prepared a flat sheet polyvinylidene fluoride-co-hexafluoropropylene (PVDF-HFP) asymmetric membrane and its permeate flux was evaluated by the DCMD process. Huo et al. [22] reported evaluation of a flat sheet polyvinylidene fluoride (PVDF) membrane supported by a polyester (PET) filament woven fabric with waterand-oil repellent finish for desalination by DCMD. Qtaishat et al. [23] examined membrane fabrication parameters such as type and concentration of SMMs, solvent type and evaporation time before gelation for the performance improvement of SMMs-blended PEI membranes in the DCMD process, and found that most of the SMMs modified PEI membranes achieved better permeate flux than that of a commercial PTFE membrane. Recently, Prince et al. [24] presented a triple layer hydrophobic/hydrophilic membrane for desalination by air gap membrane distillation (AGMD), consisting of a bottom layer of hydrophilic polyethylene terephthalate (PET), an intermediate layer with a casted PVDF by immersion precipitation method and an electrospun PVDF nanofibers layer on the top. On the other hand, a limited number of theoretical approaches on the fundamentals in heat and mass transfer in the hydrophobic/hydrophilic (or hydrophobic) composite membrane have been reported $[18,25,26]$.

All of the aforementioned research studies focused on theoretical modeling of the DCMD process using a composite membrane were based on a length-averaged lumped model that ignores spatial variations in both retentate and permeate flows in order to simulate the overall process affecting the flux. In addition, unlike a theoretical approach of the heat transfer through the composite membrane, it was assumed that the mass transfer occurs only through the pores of the hydrophobic active layer, i.e., an effective open area for diffusion, where the active layer at the permeate side is not covered by the support layer. In this study, therefore, the experimental and the theoretical investigations are simultaneously carried out to achieve a more comprehensive and systematic understandings on the fundamentals in heat and mass transfer through a commercial flat sheet composite membrane. The main focus of this study is to develop an integrated DCMD model, which consists of mass, momentum, species and energy balances on both bulk feed and permeate flows, coupled with the heat transfer across the membrane and through the boundary layers adjacent to the membrane surfaces and the mass 
transfer of water vapor through the composite membrane. The commercial composite membrane used is comprised of an active layer of polytetrafluoroethylene (PTFE) and a scrim-backing support layer of polypropylene (PP), and its permeate flux is tested in the DCMD process. The experimental and numerical results are compared to evaluate the developed model. Further investigations have been conducted to identify the influence of the surface porosity and the thickness of active and support layers on the permeate flux and performance ratio of the composite membrane.

\section{Experimental}

\subsection{Composite membrane characterization}

Morphology and structure analysis of a commercial PTFE/PP composite membrane are undertaken using field emission scanning electron microscopy (FE-SEM) (Quanta 200 FEG, FEI). A porometer (Porolux 1000, IB-FT GmbH) is used to measure the mean flow pore size, first bubble point and pore size distribution. Membrane thickness is measured using a digital micrometer (DML 3032, Digital Micrometers). Porosity is determined by using the method illustrated by Palacio et al. [28].

Fig. 1 presents the SEM images of a commercially available PTFE/PP composite membrane. From top left in a clockwise direction these are shown at 100x, 500x, 1,000x and 10,000x magnifications. As shown in top right of Fig. 1, the PTFE active layer (dark grey) is partially covered by the PP support layer (white grey). From the surface structure of the PTFE active layer shown in bottom left of Fig. 1, it appears that the knot-fibril net structured PTFE active layer has a higher surface porosity than that of the PP scrim support layer. As shown in Table 1, it is clear that the active layer is thinner than that of the scrim support layer so that it will be useful to reduce the mass transfer resistance and increase the heat transfer resistance. Due to the use of the scrim support layer, however, it should also affect DCMD permeate flux by partially covering the active layer, resulting in a decrease in the effective open area for diffusion. The thickness, porosity, mean pore size and LEPw of both active and scrim support layer membranes are given in Table 1.

\subsection{Experimental set-up and procedure}

A commercial hydrophobic microporous PTFE/PP composite membrane has been tested for desalting real Red Sea water using the DCMD configuration, as shown in Fig. 2. A membrane specimen of $5 \mathrm{~cm} \times 5 \mathrm{~cm}$ is tested in a DCMD flat sheet module made of polymethyl methacrylate material. The channel height is $3 \mathrm{~mm}$ for both feed and permeate sides. A polypropylene mesh spacer has been used at both sides of the composite membrane as a support and turbulence promoter. Detailed spacer specifications provided by the manufacturer are shown in Table 2. Red Sea water is collected from the intake pipe (before pretreatment) of a SWRO commercial plant at KAUST. The collected seawater is filtered through a $10 \mu \mathrm{m}$ filter to remove large suspended solids and then used as a DCMD feed for all DCMD experiments without any further pretreatment. The Red Sea water is heated to the desired feed temperature and then circulated through the active layer side of the membrane, while deionized (DI) water is circulated through the support layer side of the membrane in a counter-current flow configuration. Feed and permeate temperatures are kept constant by using a heater and chiller, respectively. The increase in the permeate weight is measured using an electronic balance (ML3002E Precision Balance, Mettler Toledo) and recorded via data acquisition software (LabView). Temperature, pressure and flow rate at both inlet and outlet of the module are simultaneously monitored at both feed and 
permeate sides. Salt concentrations at both feed and permeate solutions are measured using conductivity meters (Oakton Eutech Instruments).

DCMD performance of the composite PTFE/PP membrane using Red Sea water as a feed solution has been tested by varying the inlet feed temperature in the range of $40{ }^{\circ} \mathrm{C}-80{ }^{\circ} \mathrm{C}$ while keeping inlet permeate temperature constant at $10{ }^{\circ} \mathrm{C}, 20^{\circ} \mathrm{C}$ and $30{ }^{\circ} \mathrm{C}$, respectively. Here, the flow rates of bulk feed and permeate solutions are kept constant at 2.0 1/min and $2.5 \mathrm{l} / \mathrm{min}$, respectively. Also, in order to examine an effect of feed water salinity on the permeate flux, additional experiments have been conducted using DI water in both feed and permeate sides, by varying the inlet feed temperature from $40{ }^{\circ} \mathrm{C}$ to $80{ }^{\circ} \mathrm{C}$ at constant inlet permeate temperature of $20^{\circ} \mathrm{C}$. All the experiments have been performed more than three times for reproducibility and the uncertainty in the measured permeate fluxes is found to be less than $\pm 4 \%$.

\section{Theoretical approach}

Due to the temperature polarization effect in DCMD process, the temperatures at both liquid-vapor interfaces are different with the temperatures at both bulk phases, respectively. This temperature gradient between the liquid-vapor interfaces induces the vapor partial pressure difference through the composite membrane, i.e., the driving force of DCMD process. Therefore, the mass transfer of water vapor occurs through a microporous composite membrane, coupled with heat transfer across the boundary layers adjacent to the membrane surfaces and through the membrane, as shown in Fig. 3.

\subsection{Mass transfer through the membrane}

The water vapor passes through the dry membrane pores, driven by the vapor partial pressure difference imposed between the liquid-vapor interfaces. The mass transport through the composite membrane can be described by two individual transfer paths: (i) PTFE active layer not covered by PP scrim support layer at the permeate side (i.e., effective open area for diffusion) and (ii) composite PTFE active and PP support layers. This effective open area can be expressed by the surface porosity $\varepsilon_{s}$, defined as a fraction of the surface area of PP support layer over the surface area of PTFE membrane. The surface porosity is estimated using the CAD software based on the SEM images shown in Fig. 1, and its value is found to be 0.42 , which means that approximately $58 \%$ of the PTFE membrane is covered by the PP support layer. The permeate fluxes through the PTFE active layer and composite PTFE/PP layer, $J_{a l}$ and $J_{a l-s l}$, can be described as follows:

$$
\begin{aligned}
& J_{a l}=C_{a l}\left(P_{f, m}-P_{i, m}\right) \\
& J_{a l-s l}=C_{a l-s l}\left(P_{f, m}-P_{p, m}\right)
\end{aligned}
$$

where $C_{a l}$ is the membrane distillation coefficient through the active layer only and $C_{a l-s l}$ is the membrane distillation coefficient through the active and scrim support layers. $P_{f, m}$ and $P_{p, m}$ are the water vapor pressures at the liquid-vapor interface on the feed and permeate sides of the composite membrane, respectively. $P_{i, m}$ is the water vapor pressure at the liquid-vapor interface on the permeate side of the PTFE active layer. The water vapor pressure at the feed side can be determined with the solution's molar fraction. For a dilute aqueous solution of salts, the following approximation is often considered [29]:

$P_{f, m}=\left(1-x_{f}\right) P_{w, m}$ 
where $x_{f}$ is the molar fraction of non-volatile solute and $P_{w, m}$ is the pure water vapor pressure and can be evaluated with Antoine equation as follows:

$$
P_{w, m}=\exp \left(23.1964-\frac{3816.44}{T-46.13}\right)
$$

By taking the effective open area into account, therefore, the total local permeate flux $J(z)$ across the composite membrane can be given by:

$J(z)=\varepsilon_{s} J_{a l}+\left(1-\varepsilon_{s}\right) J_{a l-s l}$

The mean permeate flux over the membrane length $L$ is evaluated as $[1,6,7,15]$ :

$J_{m}=\frac{1}{L} \int_{0}^{L} J(z) d z$

where $J(z)$ is the local permeate flux expressed in Eq. (5).

A schematic of mass transfer mechanism through the composite membrane is illustrated in Fig. 4. In order to estimate the permeate flux through the composite membrane in DCMD, Knudsen diffusion-Molecular diffusion-Poiseuille flow transition model, i.e., dusty gas model $[1,2,29,30]$, has been used in this study. The dusty gas model has been widely employed to predict the DCMD permeate flux $[1,2,29,30]$. The membrane distillation coefficient for each active and support layer is as follows [1,2,29,30]:

$C_{i}=\left(R_{K}+R_{M}\right)^{-1}+R_{P}^{-1}, i=$ PTFE, $P P$

where $R_{K}^{-1}=C_{K}\left(M_{w} / R T_{m}\right)^{0.5}, R_{M}^{-1}=C_{M}\left(D M_{w} / P_{a M} R T_{m}\right)$ and $R_{P}^{-1}=C_{P}\left(P_{m} M_{W} / \mu R T_{m}\right) . C_{K}, C_{M}$ and $C_{P}$ represent the individual contribution of Knudsen diffusion $\left(C_{K}=r \varepsilon / \tau \delta\right)$, molecular diffusion $\left(C_{M}=\varepsilon / \tau \delta\right)$ and Poiseuille flow $\left(C_{P}=r^{2} \varepsilon / \tau \delta\right)$, respectively. $P_{a M}$ is the log-mean air pressure at the both sides of the membrane, $P_{m}$ is the mean water vapor pressure inside the membrane, $P_{m}=\left(P_{f, m}+P_{i, m}\right) / 2$ for the active layer and $P_{m}=\left(P_{f, m}+P_{p, m}\right) / 2$ for the active/support layers. The binary diffusion coefficient $D$ is calculated by FullerSchettler-Giddings empirical equation, which can be expressed as $D=1.19 \times 10^{-4}\left(T_{m}^{1.75} / P_{m}\right)$.

As shown in Fig. 4, the membrane distillation coefficient through the composite PTFE/PP layer in series is equal to the inverse of the total mass transfer resistance [31]. Then, the membrane distillation coefficients for each mass transfer path can be given by:

$C_{a l}=C_{P T F E}$ for $\varepsilon_{s}$

$C_{a l-s l}=\left(1 / C_{P T F E}+1 / C_{P P}\right)^{-1}$ for $1-\varepsilon_{s}$

\subsection{Heat transfer through the membrane}

As shown in Fig. 3, the bulk feed and permeate temperatures differ from the corresponding temperatures at the liquid-vapor interface on the feed and permeate sides of the composite membrane. For the estimation of those interface temperatures, the heat transfer process in DCMD, which involves the heat transferred across the boundaries of the feed side $\left(Q_{f}\right)$, permeate side $\left(Q_{p}\right)$ and through the composite membrane $\left(Q_{m}\right)$, has to be considered, as shown in Fig. 5.

Firstly, the heat transfer across the boundary layer of the feed side, $Q_{f}$, can be described by considering convection and sensible heat $[1,6,7,15,29,32]$. 
$Q_{f}=\left(h_{f}+J c_{p, f}\right)\left(T_{f}-T_{f, m}\right)$

where $T_{f}$ is the bulk feed temperature, $T_{f, m}$ is the temperature at the liquid-vapor interface on the feed side of the composite membrane and $c_{p, f}$ is the specific heat capacity of the bulk feed.

Secondly, the heat transfer by latent heat, conduction and sensible heat through the PTFE active layer and composite PTFE/PP layer, $Q_{m, a l}$ and $Q_{m, a l-s l}$, respectively, can be estimated as [1,6,7,15,29,32]:

$$
\begin{aligned}
& Q_{m, a l}=\left[J_{a l} \Delta H_{a l}+\left(\frac{1}{R_{m, a l}}+J_{a l} c_{p, w}\right)\left(T_{f, m}-T_{i, m}\right)\right] \\
& Q_{m, a l-s l}=\left[J_{a l-s l} \Delta H_{a l-s l}+\left(\frac{1}{R_{m, a l-s l}}+J_{a l-s l} c_{p, w}\right)\left(T_{f, m}-T_{p, m}\right)\right]
\end{aligned}
$$

where $\Delta H$ is the enthalpy of evaporation at the mean temperature through the membrane $T_{m}, T_{m}=\left(T_{f, m}+T_{i, m}\right) /$ 2 for the active layer and $T_{m}=\left(T_{f, m}+T_{p, m}\right) / 2$ for the active/support layers, $c_{p, w}$ is the specific heat capacity of water vapor and $T_{i, m}$ is the temperature at the liquid-vapor interface on the permeate side of the active layer.

By incorporating the surface porosity into Eqs. (11) and (12), therefore, the overall heat transfer through the composite membrane, $Q_{m}$, is given by:

$Q_{m}=\varepsilon_{s} Q_{m, a l}+\left(1-\varepsilon_{s}\right) Q_{m, a l-s l}$

In order to determine the $T_{i, m}$ in Eq. (11), the following heat transfer equation is additionally established.

$$
Q_{s}=\left(J_{a l} c_{p, w}+\frac{k_{w}}{\delta_{P P}}\right)\left(T_{i, m}-T_{p, m}\right)
$$

In Eqs. (11) and (12), the thermal resistance, $R_{m}$, for the conduction through each heat transfer path can be described as:

$$
\begin{aligned}
& R_{m, a l}=\frac{\delta_{P T F E}}{k_{m, P T F E}} \\
& R_{m, a l-s l}=\left(\frac{\delta_{P T F E}}{k_{m, P T F E}}+\frac{\delta_{P P}}{k_{m, P P}}\right)
\end{aligned}
$$

where $k_{m, i}=\left[\varepsilon_{i} / k_{g}+\left(1-\varepsilon_{i}\right) / k_{p, i}\right]^{-1}, i=$ PTFE, PP. Here, $k_{m}$ is the effective thermal conductivity of the membrane [23]. $k_{g}$ and $k_{p}$ are the thermal conductivities of gases in the pores and membrane material, respectively.

Finally, the heat transfer across the boundary layer of the permeate side, $Q_{p}$, can be expressed by convection and sensible heat $[1,29,32]$.

$$
Q_{p}=\left(h_{p}+J c_{p, w}\right)\left(T_{p, m}-T_{p}\right)
$$

where $T_{p}$ is the bulk permeate temperature and $T_{p, m}$ is the temperature at the liquid-vapor interface on the permeate side of the composite membrane.

At the steady state, the overall heat transfer through the whole DCMD process is given by $[1,29,32]$ :

$Q=Q_{f}=Q_{m}=Q_{p}$

$Q_{m, a l}=Q_{s}$ 
In Eqs. (10) and (17), the convective heat transfer coefficients at the feed and permeate boundary layers, $h_{f}$ and $h_{p}$, are estimated by using the modified Dittus-Boelter correlation for the spacer filled channels as follows [2,33-39]:

$$
\begin{aligned}
& N u=\frac{h d_{h}}{k}=0.023 k_{d c} \operatorname{Re}^{0.8} \operatorname{Pr}^{0.33} \\
& k_{d c}=1.654\left(\frac{d_{f}}{h_{s}}\right)^{-0.039} \varepsilon_{s p}^{0.75}\left[\sin \left(\frac{\theta}{2}\right)\right]^{0.086} \\
& \varepsilon_{s p}=1-\frac{\pi d_{f}^{2}}{2 l_{m} h_{s} \sin \theta}
\end{aligned}
$$

where $\operatorname{Re}=\rho v d_{h} / \mu, d_{h}=\frac{4 \varepsilon_{s p}}{2\left(w_{c}+h_{c}\right) / w_{c} h_{c}+4(1-\varepsilon) / d_{f}}$ and $\operatorname{Pr}=\mu c_{p} / k$. Here, $d_{f}$ is the diameter of spacer filaments, $l_{m}$ is the mesh size, $k_{d c}$ is the spacer factor, $h_{s}$ is the spacer thickness, $h_{c}$ is the channel height, $w_{c}$ is the channel width, $\theta$ is the hydrodynamic angle (in degree) and $\varepsilon_{s p}$ is the spacer porosity.

\subsection{Transport models of feed and permeate sides}

To demonstrate the flat sheet module transport behavior, a mathematical model is formulated by considering mass, momentum, species and energy balances. In this study, the transport equations for both bulk feed and permeate flows are derived based on the several assumptions [1]. In the feed side, the momentum, mass, species and energy balances can be described by coupled differential equations in terms of pressure $\left(P_{f}\right)$, velocity $\left(v_{f}\right)$, concentration $\left(x_{f}\right)$ and temperature $\left(T_{f}\right)$ as follows $[1,6,7,15,32]$ :

$\frac{d P_{f}}{d z}=-\frac{3 \mu_{f}}{h_{c}^{2}} v_{f}$

$\frac{1}{X_{f}} \frac{d v_{f}}{d z}-\frac{v_{f}}{X_{f}^{2}}\left(\frac{M_{s}}{\rho_{s}}-\frac{M_{w}}{\rho_{w}}\right) \frac{d x_{f}}{d z}=-\frac{J}{M_{f} \varepsilon_{s p} h_{c}}$

$\frac{x_{f}}{X_{f}} \frac{d v_{f}}{d z}+\frac{v_{f} M_{w}}{\rho_{w} X_{f}^{2}} \frac{d x_{f}}{d z}=0$

$$
\frac{d \rho_{f} v_{f} c_{p, f} T_{f}}{d z}=-\frac{Q_{f}}{\varepsilon_{s p} h_{c}}
$$

where $d_{h}$ is the channel hydraulic diameter, $x_{f}$ is the molar fraction of feed solution, $X_{f}$ is the molar volume of feed solution, $M_{s}$ is the molecular weight of salt, $M_{w}$ is the molecular weight of water and $M_{f}$ is the molecular weight of feed solution.

The boundary conditions for the pressure, velocity, concentration and temperature at the feed side are as follows:

$$
P_{f}(L)=P_{0}, \quad v_{f}(0)=v_{f, i n}=\frac{V_{f, i n}}{\varepsilon_{s p} h_{c} w_{c}}, \quad x_{f}(0)=x_{f, \text { in }}, \quad T_{f}(0)=T_{f, \text { in }}
$$

In the permeate side, the momentum, mass and energy balances can be described by coupled differential equations in terms of pressure $\left(P_{p}\right)$, velocity $\left(v_{p}\right)$ and temperatuere $\left(T_{p}\right)[1,32]$. 
$\frac{d P_{p}}{d z}=-\frac{3 \mu_{p}}{h_{c}^{2}} v_{p}$

$\frac{d v_{p}}{d z}=-\frac{J X_{p}}{M_{p} \varepsilon_{s p} h_{c}}$

$\frac{d \rho_{p} v_{p} c_{p, p} T_{p}}{d z}=-\frac{Q_{p}}{\varepsilon_{s p} h_{c}}$

The boundary conditions for the pressure, velocity and temperature at the permeate side are as follows:

$$
P_{p}(0)=P_{0}, \quad v_{p}(L)=v_{p, i n}=\frac{V_{p, i n}}{\varepsilon_{s p} h_{c} w_{c}}, \quad T_{p}(L)=T_{p, \text { in }}
$$

In order to evaluate the performance of DCMD process using a commercial composite membrane, the performance ratio $(P R)$ are defined as [1]:

$$
P R=\frac{1}{L} \int_{0}^{L} \eta(z) d z
$$

where $\eta(z)$ is the local performance ratio, defined as the ratio of the vaporization heat associated with the permeate flux to the heat transferred through the membrane, and given by [1]:

$$
\eta(z)=\frac{\left.\varepsilon J(z) \Delta H\right|_{a l}+\left.(1-\varepsilon) J(z) \Delta H\right|_{a l-s l}}{Q_{m}}
$$

\subsection{Solution procedure}

A flow chart of the solution procedure is shown in Fig. 6. The set of coupled ordinary differential equations for the feed side, namely Eqs. (23)-(26), and for the permeate side, namely Eqs. (28)-(30), are discretized with the finite volume method and solved in conjunction with the boundary conditions for both feed and permeate sides, namely Eqs. (27) and (31), and the characterization of the membrane, namely Eqs. (10), (13) and (17)(19) for heat transfer and Eqs. (1)-(9) for mass transfer. The convergence criteria for a steady-state is $\left|s^{\mathrm{n}+1}-s^{\mathrm{n}}\right|<10^{-6}$, where $s$ is any variable $\left(P_{f}, v_{f}, x_{f}, T_{f}, P_{p}, v_{p}, T_{p}\right)$ at all points and $n$ is the iteration level. Broyden's method is employed to solve the system of ordinary differential equations. Thermophysical properties of pure water and seawater are obtained from [40]. The salinity of Red Sea water used is measured to be $4.0 \mathrm{wt} \%$. All of the governing equations are solved by developing a source code written in Microsoft Visual Studio 2010 Fortran 90 on Intel®Core ${ }^{\mathrm{TM}}$ i7-3770 CPU.

\section{Results and discussion}

\subsection{Performance evaluation and model validation}

Fig. 7 presents the mean permeate flux (experimental and simulated) and performance ratio with respect to bulk feed temperature at an inlet permeate temperature of $10{ }^{\circ} \mathrm{C}$ using Red Sea water. It is shown that, with an increase in the inlet feed temperature, the measured permeate flux increases exponentially from $18 \mathrm{~kg} / \mathrm{m}^{2} \mathrm{~h}$ to 96 $\mathrm{kg} / \mathrm{m}^{2} \mathrm{~h}$, as a consequence of a significant increase in the driving force, which can be easily expected by the Antoine equation expressed in Eq. (4). The performance ratio, meanwhile, increases gradually from $35 \%$ to $85 \%$ with increasing inlet feed temperature as the vaporization heat is greater than the heat loss by conduction 
through the composite membrane which becomes greater at higher transmembrane temperature difference [1], as expected from Eq. (33).

Using Red Sea water and DI water as a feed solution, the effect of the bulk feed temperature on the permeate flux (experimental and simulated) and performance ratio at an inlet permeate temperature of $20^{\circ} \mathrm{C}$ is shown in Fig. 8. With an increase in the inlet feed temperature from $40{ }^{\circ} \mathrm{C}$ to $80{ }^{\circ} \mathrm{C}$ using Red Sea water, as shown in Fig. 8(a), the measured permeate flux increases from $14 \mathrm{~kg} / \mathrm{m}^{2} \mathrm{~h}$ to $89 \mathrm{~kg} / \mathrm{m}^{2} \mathrm{~h}$, while the model prediction shows the increase of permeate flux from $10 \mathrm{~kg} / \mathrm{m}^{2} \mathrm{~h}$ to $93 \mathrm{~kg} / \mathrm{m}^{2} \mathrm{~h}$. The performance ratio increases asymptotically from $43 \%$ to $86 \%$. As illustrated in Fig. 8(b), when DI water is used as a feed solution, the measured permeate flux increases from 16 to $94 \mathrm{~kg} / \mathrm{m}^{2} \mathrm{~h}$, whereas the model-based permeate flux increases from $10 \mathrm{~kg} / \mathrm{m}^{2} \mathrm{~h}$ to $97 \mathrm{~kg} / \mathrm{m}^{2} \mathrm{~h}$. Also, the performance ratio increases gradually from $45 \%$ to $87 \%$ with increasing inlet feed temperature. When comparing the permeate flux for Red Sea and DI waters, it is shown that the MD flux is not significantly affected by the feed water salinity [1-10,14]. It is well known that in the MD process, the effect of concentration polarization on the permeate flux is much less significant than that of temperature polarization.

At an inlet permeate temperature of $30{ }^{\circ} \mathrm{C}$ the variations of the permeate flux (experimental and simulated) and performance ratio with regard to bulk feed temperature are shown in Fig. 9. With increasing inlet feed temperature from $40{ }^{\circ} \mathrm{C}$ to $80{ }^{\circ} \mathrm{C}$, the measured permeate flux increases from $8 \mathrm{~kg} / \mathrm{m}^{2} \mathrm{~h}$ to $76 \mathrm{~kg} / \mathrm{m}^{2} \mathrm{~h}$ and the model-based flux increases from 6 to $83 \mathrm{~kg} / \mathrm{m}^{2} \mathrm{~h}$, while the performance ratio increases asymptotically from $52 \%$ to $87 \%$.

From the experimental results above, the maximum DCMD permeate flux of the composite PTFE/PP membrane with Red Sea water, i.e., $96 \mathrm{~kg} / \mathrm{m}^{2} \mathrm{~h}$, is achieved at the inlet feed and permeate temperatures of $80{ }^{\circ} \mathrm{C}$ and $10{ }^{\circ} \mathrm{C}$, respectively, due to the higher transmembrane temperature difference as a driving force. It is also noted that the performance ratio increases with an increase in the inlet permeate temperature, which is attributed to a decrease of the conductive heat loss through the membrane. It is also shown that an increase of performance ratio at lower feed temperatures is significantly greater compared to that at higher feed temperatures due to the exponential increase of the partial vapor pressure with feed temperature. As shown in Figs. 7-9, the model predictions on the permeate flux are in good accordance with the measured results at feed temperatures above $50{ }^{\circ} \mathrm{C}$ or permeate temperatures above $30{ }^{\circ} \mathrm{C}$, i.e., $10 \%$ maximum deviation, but relatively large deviations are observed at lower permeate temperatures less than $30{ }^{\circ} \mathrm{C}$ with the feed temperature of $40{ }^{\circ} \mathrm{C}$ in Figs. 7 and 8, which may be attributed to an underestimation of the membrane distillation coefficient, but also could be due to the low flux obtained under these conditions, hence a lower accuracy in the measurements.

In addition, the mean permeate fluxes through the PTFE active layer and the composite PTFE/PP layer, i.e., $J_{m, a l}$ and $J_{m, a l-s l}$, are compared with regard to both inlet feed and permeate temperatures by keeping the other operating parameters constant as before. As depicted in Fig. 10, it is noted that the order of magnitude of mean permeate flux through the active layer is significantly greater than that through the composite layer. Therefore, the permeate flux through the composite PTFE/PP layer can be ignored in the consideration of mass transfer pathways for the composite PTFE/PP membrane considered in this study.

\subsection{Influence of surface porosity}


The effect of the surface porosity on DCMD performance using Red Sea water is theoretically examined with respect to surface porosity ranging from $30 \%$ to $70 \%$ and inlet feed temperature in the range of $40{ }^{\circ} \mathrm{C}$ to $80{ }^{\circ} \mathrm{C}$ at the inlet permeate temperature of $25{ }^{\circ} \mathrm{C}$ under given characteristics of the composite membrane and operating conditions.

Fig. 11 presents the effect of the surface porosity and inlet feed temperature on the permeate flux and performance ratio, respectively. As can be observed in Fig. 11(a), the permeate flux increases with an increase in the surface porosity and inlet feed temperature. Since, as stated before, the permeate flux through the composite PTFE/PP layer is negligible compared to that through the PTFE active layer, the permeate flux through the composite membrane increases by increasing surface porosity. Also, the higher feed temperature leads to the higher transmembrane temperature difference, which results in an increase of the driving force, yielding a higher permeate flux.

As mentioned already the performance ratio increases asymptotically with an increase in the inlet feed temperature, as shown in Fig. 11(b). The increase of the surface porosity also improves the performance ratio, which can be explained as follows. When the surface porosity increases at constant feed temperature, the thermal resistance for conductive heat transfer decreases, but the condensation temperature at the permeate side increases due to the higher local latent heat transfer induced by an increased permeate flux, resulting in a lower transmembrane temperature difference. Then, their effects on conductive heat loss through the membrane will be partially offset. Ultimately, the performance ratio will be mainly dependent of the latent heat transferred through the PTFE active layer.

\subsection{Influence of active layer thickness}

Fig. 12 shows the effect of the PTFE membrane thickness on the permeate flux and performance ratio. The process performance of the composite membrane are examined by varying the active layer thickness in the range of $20 \mu \mathrm{m}$ to $80 \mu \mathrm{m}$ and the feed temperature from $40{ }^{\circ} \mathrm{C}$ to $80{ }^{\circ} \mathrm{C}$ while keeping other operating parameters constant at the inlet permeate temperature of $25^{\circ} \mathrm{C}$.

As expected from the previous results, the permeate flux increases exponentially with an increase of the feed temperature. And the permeate flux is clearly lower at the thicker active layer, as shown in Fig. 12(a), since the membrane thickness is inversely proportional to the membrane distillation coefficient according to Eqs. (7)(9). As shown in Fig. 12(b), the performance ratio decreases marginally with increasing thickness of the active layer and a further increase of the thickness creates a plateau in the performance ratio profile. However, it has been known that the performance ratio increases gradually as the membrane thickness increases at the transmembrane temperature difference of above $10{ }^{\circ} \mathrm{C}$ [41]. In this case, on the contrary, the positive effect on the performance ratio due to an increase of the active layer thickness is counterbalanced by the reduction of latent heat. Thus, the performance ratio shows a behavior almost independent of the active layer thickness.

\subsection{Influence of support layer thickness}

The effect of the PP support layer thickness on the permeate flux and performance ratio is analyzed with regard to scrim support layer thickness in the range of $80 \mu \mathrm{m}-140 \mu \mathrm{m}$ and feed temperature in the range of $40{ }^{\circ} \mathrm{C}-80{ }^{\circ} \mathrm{C}$ while keeping other operating parameters constant at the inlet permeate temperature of $25^{\circ} \mathrm{C}$, as shown in Fig. 13. 
As presented in Fig. 13(a), as the support layer thickness increases, the permeate flux declines slightly as expected from an inverse proportional relationship between the membrane distillation coefficient and the membrane thickness in Eqs. (7)-(9) and a decrease of transmembrane temperature difference. However, its effect on the permeate flux is negligibly small compared to that of active layer thickness, especially at lower feed temperatures below $70{ }^{\circ} \mathrm{C}$, because the permeate flux occurs mainly through the PTFE active layer as stated before. Therefore, it appears that the permeate flux is almost independent of the support layer thickness. On the other hand, a higher performance ratio is achieved at the thicker scrim support layer, as shown in Fig. 13(b). This is because the reduction in the conductive heat loss through the composite membrane is more significant than the decrease in the latent heat due to the flux decline at higher support layer thickness.

\section{Conclusions}

In this paper, a direct contact membrane distillation process has been studied, together with a new integrated theoretical model, to describe the permeate flux and performance ratio of a microporous hydrophobic composite membrane, comprising both an active layer of polytetrafluoroethylene and a scrim-backing support layer of polypropylene. The theoretical model developed involves the structural characteristics of the membrane, the heat transfer mechanism and physical nature of mass transport through the composite membrane, and the mass, momentum, species and energy balances for both bulk feed and permeate flows in the spacer filled channels. The model predictions are validated in comparison with measured data. Good agreement between prediction results and experimental data are observed. It is noted that in the consideration of mass transfer pathways of the composite membrane, the permeate flux through the composite layer can be ignored as compared to that only through the active layer. In addition, the influences of the surface porosity and the thickness of active and support layers on the process performance of composite membrane have been examined. Among these parameters considered, the surface porosity is found to be a significant factor influencing the permeate flux and performance ratio, whereas the relative effect of the surface porosity on the performance ratio is less distinctive than on the permeate flux.

\section{Acknowledgements}

This research was supported by Basic Science Research Program through the National Research Foundation of Korea(NRF) funded by the Ministry of Science, ICT \& Future Planning (NRF-2014R1A2A2A01006899)

\section{Nomenclature}

C

$c_{p}$

D

$d_{h}$

$h$

$h_{c}$

$\Delta H$
Membrane distillation coefficient $\left[\mathrm{kg} / \mathrm{m}^{2} \mathrm{sPa}\right]$

Specific heat capacity $[\mathrm{kJ} / \mathrm{kmolK}]$

Diffusion coefficient $\left[\mathrm{m}^{2} \mathrm{~s}\right]$

Hydraulic diameter [m]

Convective heat transfer coefficient $\left[\mathrm{W} / \mathrm{m}^{2} \mathrm{~K}\right]$

Channel height [m]

Enthalpy of water evaporation $[\mathrm{J} / \mathrm{kg}]$ 


\section{ACCEPTED MANUSCRIPT}

$\begin{array}{ll}J & \text { Permeate flux }\left[\mathrm{kg} / \mathrm{m}^{2} \mathrm{~h}\right] \\ k & \text { Conductive heat transfer coefficient }\left[\mathrm{W} / \mathrm{m}^{2} \mathrm{~K}\right] \\ L & \text { Membrane length }[\mathrm{m}] \\ M & \text { Molecular weight }[\mathrm{kg} / \mathrm{kmol}] \\ P & \text { Pressure [Pa] } \\ P R & \text { Performance ratio [\%] } \\ Q & \text { Heat flux [W] } \\ R_{K} & \text { Correlation form of Knudsen diffusion } \\ R_{M} & \text { Correlation form of Molecular diffusion } \\ R_{P} & \text { Correlation form of Poiseuille flow } \\ R_{m, P T F E} & \text { Thermal resistance for the conduction through the active layer } \\ R_{m, P T F E-P P} & \text { Thermal resistance for the conduction through the active/support layers } \\ T & \left.\text { Temperature [ }{ }^{\circ} \mathrm{C}\right] \\ V & \text { Volume flow rate }[1 / \mathrm{min}] \\ v & \text { Velocity [m/s] } \\ w_{c} & \text { Channel width [m] } \\ X & \left.\text { Molar volume [m }{ }^{3} / \mathrm{mol}\right] \\ x & \text { Molar fraction in liquid phase [-] } \\ z & \text { Axial coordinate [m] } \\ & \end{array}$

Dimensionless numbers

$\begin{array}{ll}\mathrm{Nu} & \text { Nusselt number [-] } \\ \mathrm{Pr} & \text { Prandtl number [-] } \\ \operatorname{Re} & \text { Reynolds number [-] }\end{array}$

Greek letters

$\begin{array}{ll}\delta & \text { Membrane thickness [m] } \\ \varepsilon & \text { Porosity [-] } \\ \varepsilon_{s} & \text { Surface porosity [-] } \\ \theta & \text { Hydrodynamic angle [degree] } \\ \mu & \text { Kinematic viscosity [Pas] } \\ \rho & \left.\text { Density [kg } / \mathrm{m}^{3}\right] \\ \tau & \text { Tortuosity [-] }\end{array}$

Subscripts

al Active layer

$b \quad$ Bulk 


$\begin{array}{ll}g & \text { Gas } \\ m & \text { Mean or membrane } \\ s l & \text { Support layer } \\ v & \text { Vapor } \\ w & \text { Water }\end{array}$

\section{Reference}

[1] Y.-D. Kim, K. Thu, N. Ghaffour, K.C. Ng, Performance investigation of a solar-assisted direct contact membrane distillation system, J. Membr. Sci. 427 (2013) 345-364.

[2] K.W. Lawson, D.R. Lloyd, Membrane distillation, J. Membr. Sci. 124 (1997) 1-25.

[3] S. Al-Obaidani, E. Curcio, F. Macedonio, G. DiProfio, H. Al-Hinai, E. Drioli, Potential of membrane distillation in seawater desalination: thermal efficiency, sensitivity study and cost estimation, J. Membr. Sci. 323 (2008) 85-98.

[4] M.S. El-Bourawi, Z. Ding, R. Ma, M. Khayet, A frame work for better understanding membrane distillation separation process, J. Membr. Sci. 285 (2006) 4-29.

[5] L.-H. Cheng, Y.-H. Lin, J. Chen, Enhanced air gap membrane desalination by novel finned tubular membrane modules, J. Membr. Sci. 378 (2011) 398-406.

[6] J.-G. Lee, W.-S. Kim, Numerical modeling of the vacuum membrane distillation process, Desalination 16 (2013) 46-55.

[7] J.-G. Lee, W.-S. Kim, Numerical study on multi-stage vacuum membrane distillation with economic evaluation, Desalination 339 (2014) 54-67.

[8] H. Maab, A. Al Saadi, L. Francis, S. Livazovic, N. Ghaffour, G.L. Amy, S.P. Nunes, Polyazole hollow fiber membranes for direct contact membrane distillation, Ind. Eng. Chem. Res. 52 (2013) 10425-10429.

[9] L. Francis, N. Ghaffour, A.S. Alsaadi, S.P. Nunes, G.L. Amy, PVDF hollow fiber and nanofibers membranes for fresh water reclamation using membrane distillation, J. Mater. Sci. 49 (2014) 2045-2053.

[10] L. Francis, N. Ghaffour, A.A. Alsaadi, G.L. Amy, Material gap membrane distillation: A new design for water vapor flux enhancement, J. Membr. Sci. 448 (2013) 240-247.

[11] B. Li, K.K. Sirkar, Novel membrane and device for direct contact membrane distillation-based desalination process, Ind. Eng. Chem. Res. 43 (2004) 5300-5309.

[12] T.Y. Cath, V.D. Adams, A.E. Childress, Experimental study of desalination using direct contact membrane distillation: a new approach to flux enhancement, J. Membr. Sci. 228 (2004) 5-16.

[13] J. Gilron, L. Song, K.K. Sirkar, Design for cascade of crossflow direct contact membrane distillation, Ind. Eng. Chem. Res. 46 (2007) 2324-2334.

[14] L. Francis, A.S. Alsaadi, N. Ghaffour, G.L. Amy, Performance evaluation of the DCMD desalination process under bench scale and large scale module operating conditions, J. Membr. Sci. 455 (2014) 103-112.

[15] H. Maab, L. Francis, A.S. Alsaadi, C. Aubry, N. Ghaffour, G.L. Amy, S.P. Nunes, Synthesis and fabrication of nanostructured hydrophobic polyazole membranes for low energy water recovery, J. Membr. Sci. 423-424 (2012) 11-19.

[16] H.-Y. Lee, F. He, L. Song, J. Gilron, K.K. Sirkar, Desalination with a cascade of cross-flow hollow fiber 
membrane distillation devices integrated with a heat exchanger, AIChE 57 (2011) 1780-1795.

[17] S.-M. Shim, J.-G. Lee, W.-S. Kim, Performance simulation of a multi-VMD desalination process including the recycle flow, Desalination 338 (2014) 39-48.

[18] M. Khayet, J.I. Mengual, T. Matsuura, Porous hydrophobic/hydrophilic composite membranes: Application in desalination using direct contact membrane distillation, J. Membr. Sci. 252 (2005) 101-113.

[19] D.Y. Cheng, S.J. Wiersma, Composite membranes for a membrane distillation system, US Patents 4,316,772 (1982); 4,419,242 (1983).

[20] P. Peng, A.G. Fane, X. Li, Desalination by membrane distillation adopting a hydrophilic membrane, Desalination 173 (2005) 45-54.

[21] C. Feng, R. Wang, B. Shi, G. Li, Y. Wu, Factors affecting pore structure and performance of poly(vinylidene fluoride-co-hexafluoro propylene) asymmetric porous membrane, J. Membr. Sci. 277 (2006) $55-64$.

[22] R. Huo, Z. Gu, K. Zuo, G. Zhao, Preparation and properties of PVDF-fabric composite membrane for membrane distillation, Desalination 249 (2009) 910-913.

[23] M. Qtaishat, D. Rana, M. Khayet, T. Matsuura, Preparation and characterization of novel hydrophobic/ hydrophilic polyetherimide composite membranes for desalination by direct contact membrane distillation, $\mathrm{J}$. Membr. Sci. 327 (2009) 264-273.

[24] J.A. Prince, V. Anbharasi, T.S. Shanmugasundaram, G. Singh, Preparation and characterization of novel triple layer hydrophilic-hydrophobic composite membrane for desalination using air gap membrane distillation, Sep. Sci. Technol. 118 (2013) 598-603.

[25] M. Qtaishat, M. Khayet, T. Matsuura, Guidelines for preparation of higher flux hydrophobic/hydrophilic composite membranes for membrane distillation, J. Membr. Sci. 329 (2009) 193-200.

[26] D. Winter, J. Koschikowski, D. Duver, P. Hertel, U. Beuscher, Evaluation of MD process performance: Effect of backing structures and membrane properties under different operating conditions, Desalination 323 (2013) 120-133.

[27] L. Francis, N. Ghaffour, G. Amy, Fabrication and characterization of functionally graded poly(vinylidine fluoride)-silver nanocomposite hollow fibers for sustainable water recovery, Sci. Adv. Mater. doi:10.1166/sam.2014.1980.

[28] L. Palacio, P. Prádanos, J.I. Calvo, A. Hernández, Porosity measurements by a gas penetration method and other techniques applied to membrane characterization, Thin Solid Films 348 (1999) 22-29.

[29] M. Khayet, T. Matsuura, Membrane Distillation Principles and Applications, 1st ed., Elsevier, 2011.

[30] Z. Ding, R. Ma, A.G. Fane, A new model for mass transfer in direct contact membrane distillation, Desalination 151 (2002) 217-227.

[31] Y.A. Çengel, Heat Transfer: A Practical Approach, $3^{\text {rd }}$ ed., McGraw-Hill, New York, 2007.

[32] L.-H. Cheng, P.-C. Wu, J. Chen, Modeling and optimization of hollow fiber DCMD module for desalination, J. Membr. Sci. 318 (2008) 154-166.

[33] R.W. Schofield, A.G. Fane, C.J.D. Fell, Heat and mass transfer in membrane distillation, J. Membr. Sci. 33 (1987) 299-313.

[34] G. Schock, A. Miquel, Mass transfer and pressure loss in spiral wound modules, Desalination 64 (1987) 339-352. 
[35] A.R. Da Costa, A.G. Fane, D.E. Wiley, Spacer characterization and pressure drop modelling in spacerfilled channels for ultrafiltration, J. Membr. Sci. 87 (1994) 79-98.

[36] S. Al-Sharif, M. Albeirutty, A. Cipollina, G. Micale, Modelling flow and heat transfer in spacer-filled membrane distillation channels using open source CFD code, Desalination 311 (2013) 103-112.

[37] J. Phattaranawik, R. Jiraratananon, A.G. Fane, Mass flux enhancement using spacer filled channels in direct contact membrane distillation, J. Membr. Sci. 187 (2001) 193-201.

[38] J. Phattaranawik, R. Jiraratananon, A.G. Fane, Effects of net-type spacers on heat and mass transfer in direct contact membrane distillation and comparison with ultrafiltration studies, J. Membr. Sci. 217 (2003) 193206.

[39] A.S. Alsaadi, N. Ghaffour, J.-D. Li, S. Gray, L. Francis, M. Maab, G.L. Amy, Modeling of air-gap membrane distillation process: a theoretical and experimental study, J. Membr. Sci. 445 (2013) 53-65.

[40] M.H. Sharqawy, J.H. Lienhard V, S.M. Zubair, Thermophysical properties of seawater: a review of existing correlations and data, Desalin. Water Treat. 16 (2010) 354-380.

[41] S. Al-Obaidani, E. Curcio, F. Macedonio, G.D. Profio, H. Al-Hinai, E. Drioli, Potential of membrane distillation in seawater desalination: thermal efficiency, sensitivity study and cost estimation, J. Membr. Sci. 323 (2008) 85-98. 


\section{Table captions}

Table 1 Characteristics of the PTFE/PP composite membrane.

Table 2 Specifications of the spacer.

\section{Figure captions}

Fig. 1. SEM images of a commercially available PTFE/PP composite membrane. Clockwise from top left: 100x, 500x, 1,000x and 10,000x magnifications.

Fig. 2. Schematic of the DCMD experimental set-up.

Fig. 3. Schematic of heat and mass transfer mechanisms through a composite membrane in DCMD process.

Fig. 4. Schematic diagram of mass transfer through the composite membrane.

Fig. 5. Schematic diagram of heat transfer through the composite membrane.

Fig. 6. A flow chart of the solution procedure.

Fig. 7. Effect of the inlet feed temperature on the permeate flux (experimental and simulated) and performance ratio with Red Sea water at constant inlet permeate temperature of $10^{\circ} \mathrm{C}$.

Fig. 8. Effect of the inlet feed temperature on the permeate flux (experimental and simulated) and performance ratio with (a) Red Sea water and (b) DI water at constant inlet permeate temperature of $20^{\circ} \mathrm{C}$.

Fig. 9. Effect of the inlet feed temperature on the permeate flux (experimental and simulated) and performance ratio with Red Sea water at constant inlet permeate temperature of $30^{\circ} \mathrm{C}$.

Fig. 10. Comparison of permeate flux through PTFE active layer $\left(J_{m, a l}\right)$ and composite PTFE/PP layer $\left(J_{m, a l-s l}\right)$ with respect to both inlet feed and permeate temperatures.

Fig. 11. Effect of the surface porosity and inlet feed temperature on (a) mean permeate flux $\left(\mathrm{kg} / \mathrm{m}^{2} \mathrm{~h}\right)$ and $(\mathrm{b})$ performance ratio $(\%)$.

Fig. 12. Effect of the active layer thickness and inlet feed temperature on (a) mean permeate flux $\left(\mathrm{kg} / \mathrm{m}^{2} \mathrm{~h}\right) \mathrm{and}$ (b) performance ratio (\%).

Fig. 13. Effect of the support layer thickness and inlet feed temperature on (a) mean permeate flux $\left(\mathrm{kg} / \mathrm{m}^{2} \mathrm{~h}\right) \mathrm{and}$ (b) production ratio $(\%)$. 


\section{ACCEPTED MANUSCRIPT}

Table 1 Characteristics of the PTFE/PP composite membrane.

\begin{tabular}{|c|c|c|}
\hline Material & PTFE & $\mathrm{PP}$ \\
\hline Thickness $^{\mathrm{a}}, \delta_{m}(\mu \mathrm{m})$ & $20 \pm 0.4$ & $80 \pm 1.6$ \\
\hline Porosity $^{\mathrm{a}}, \varepsilon(\%)$ & $70 \pm 5.0$ & $34 \pm 2.4$ \\
\hline Mean pore size ${ }^{\mathrm{a}}, r(\mu \mathrm{m})$ & $0.5 \pm 0.020$ & $0.1 \pm 0.004$ \\
\hline Liquid entry pressure $^{\mathrm{b}}, L E P_{w}(\mathrm{kPa})$ & 207 & 160 \\
\hline
\end{tabular}

a: measured data, b: manufacturer's data 


\section{ACCEPTED MANUSCRIPT}

Table 2 Specifications of the spacer.

\begin{tabular}{cc}
\hline Material & PP \\
\hline Spacer thickness, $d_{f}(\mathrm{~mm})$ & 0.8 \\
Filaments diameter, $h_{s}(\mathrm{~mm})$ & 0.4 \\
Angle between filaments, $\theta(\mathrm{deg})$ & 90 \\
Mesh size, $l_{m}(\mathrm{~mm})$ & 2 \\
\hline
\end{tabular}




\section{Highlights}

- Experimental and theoretical DCMD studies using commercial composite membrane

- Development and validation of integrated theoretical DCMD model of composite membrane

- Negligible effect of composite layer in mass transfer pathways of composite membrane

- Surface porosity greatly influencing the process performance of composite membrane 


\section{ACCEPTED MANUSCRIPT}

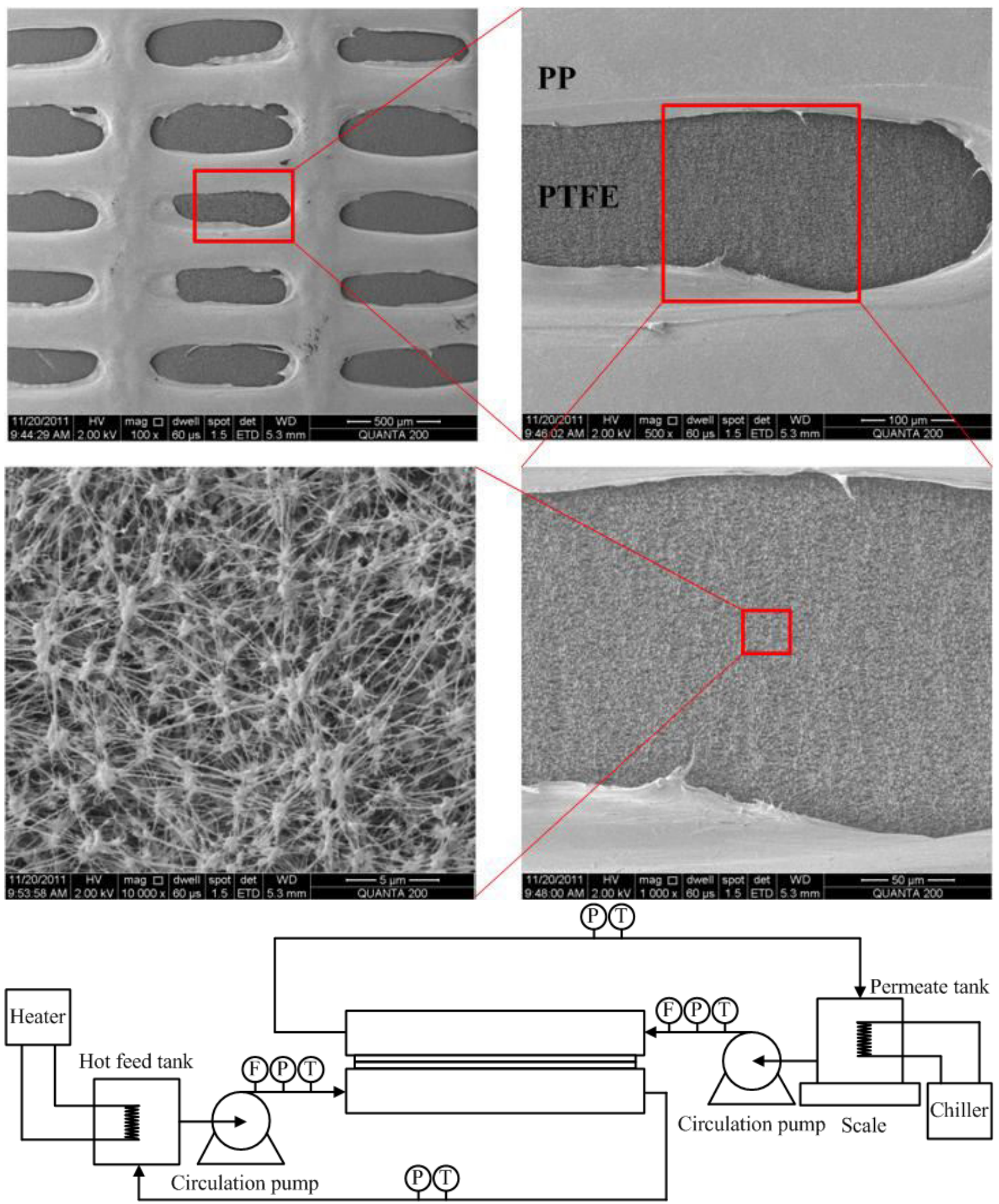




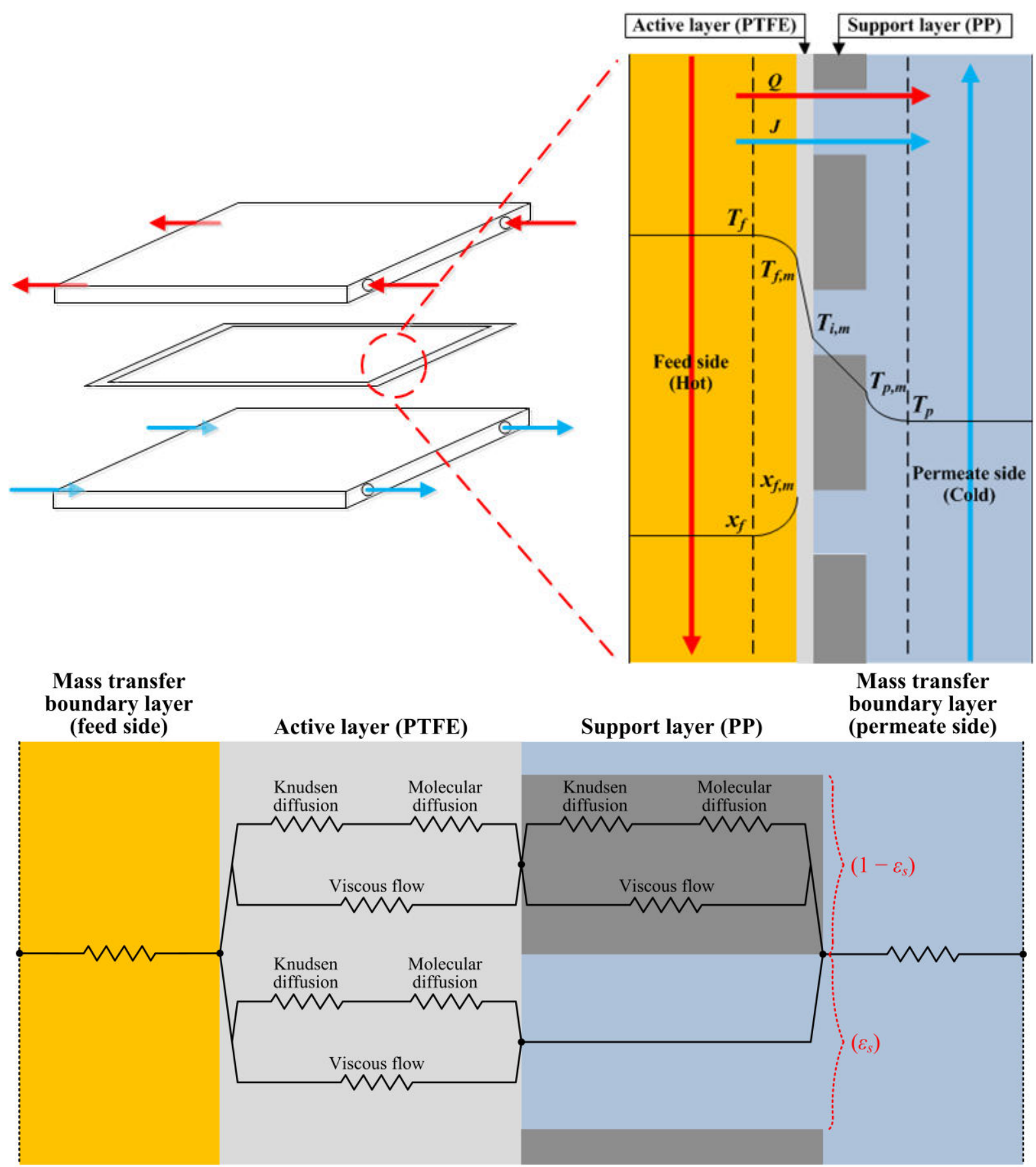




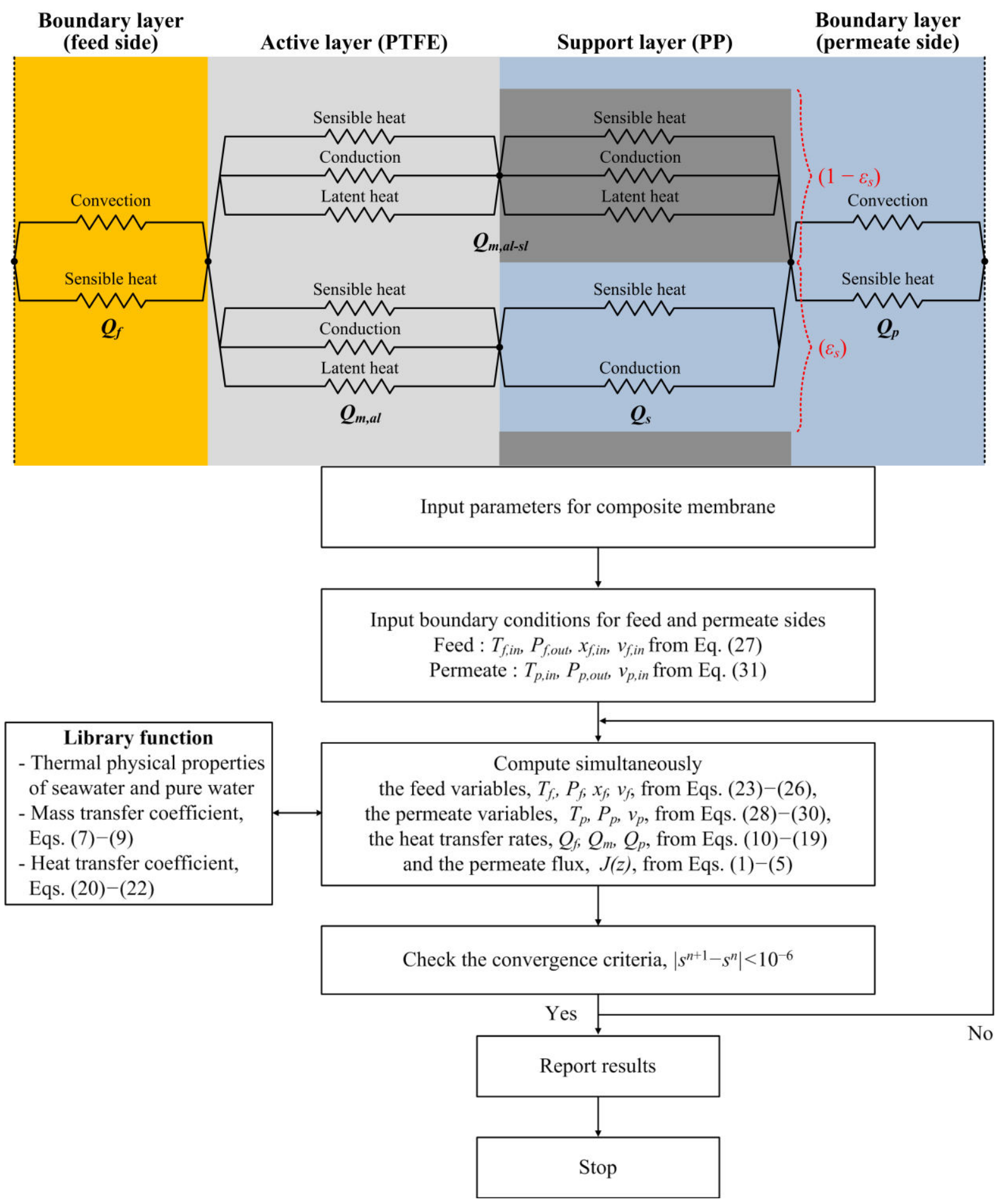



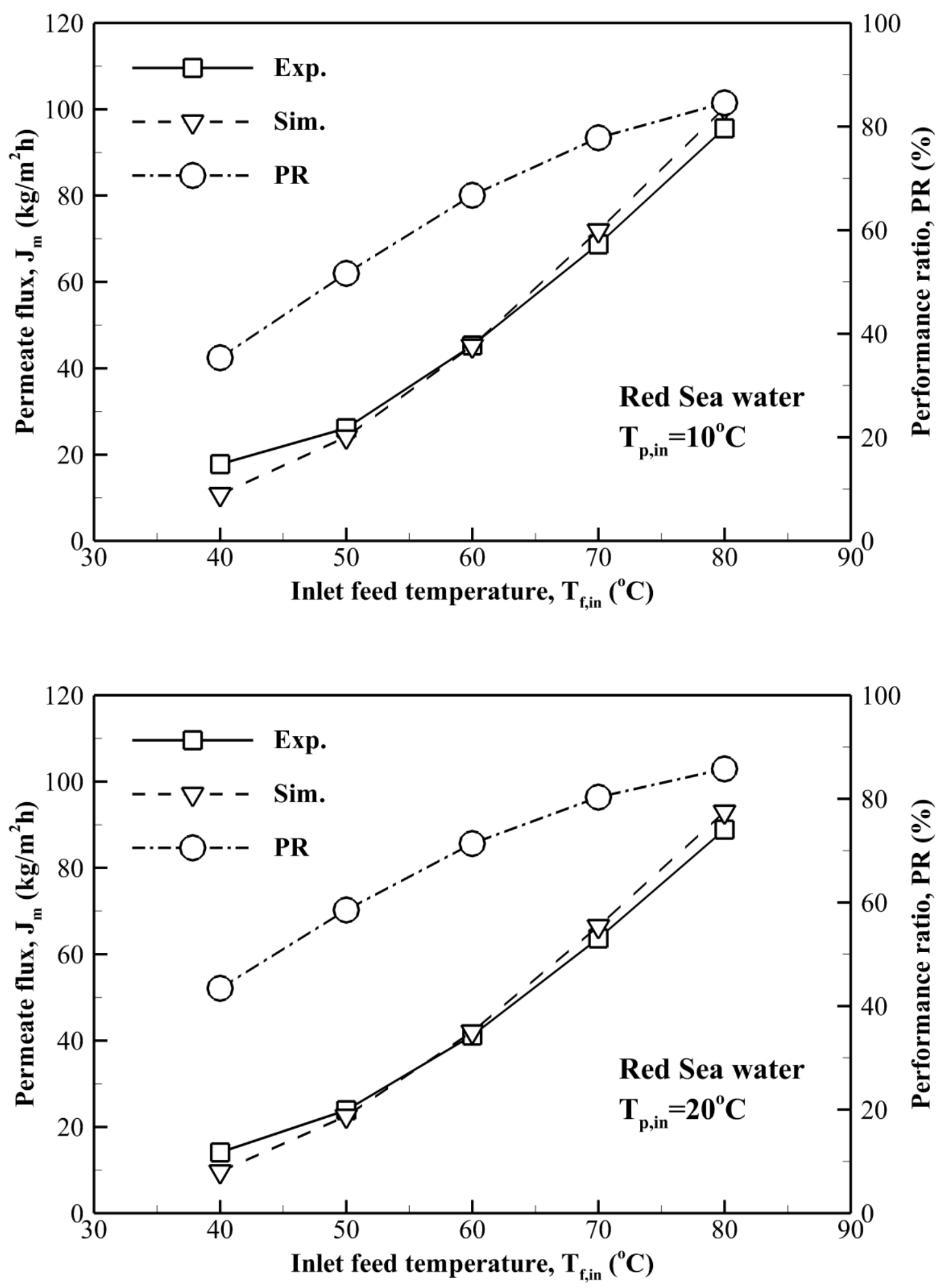

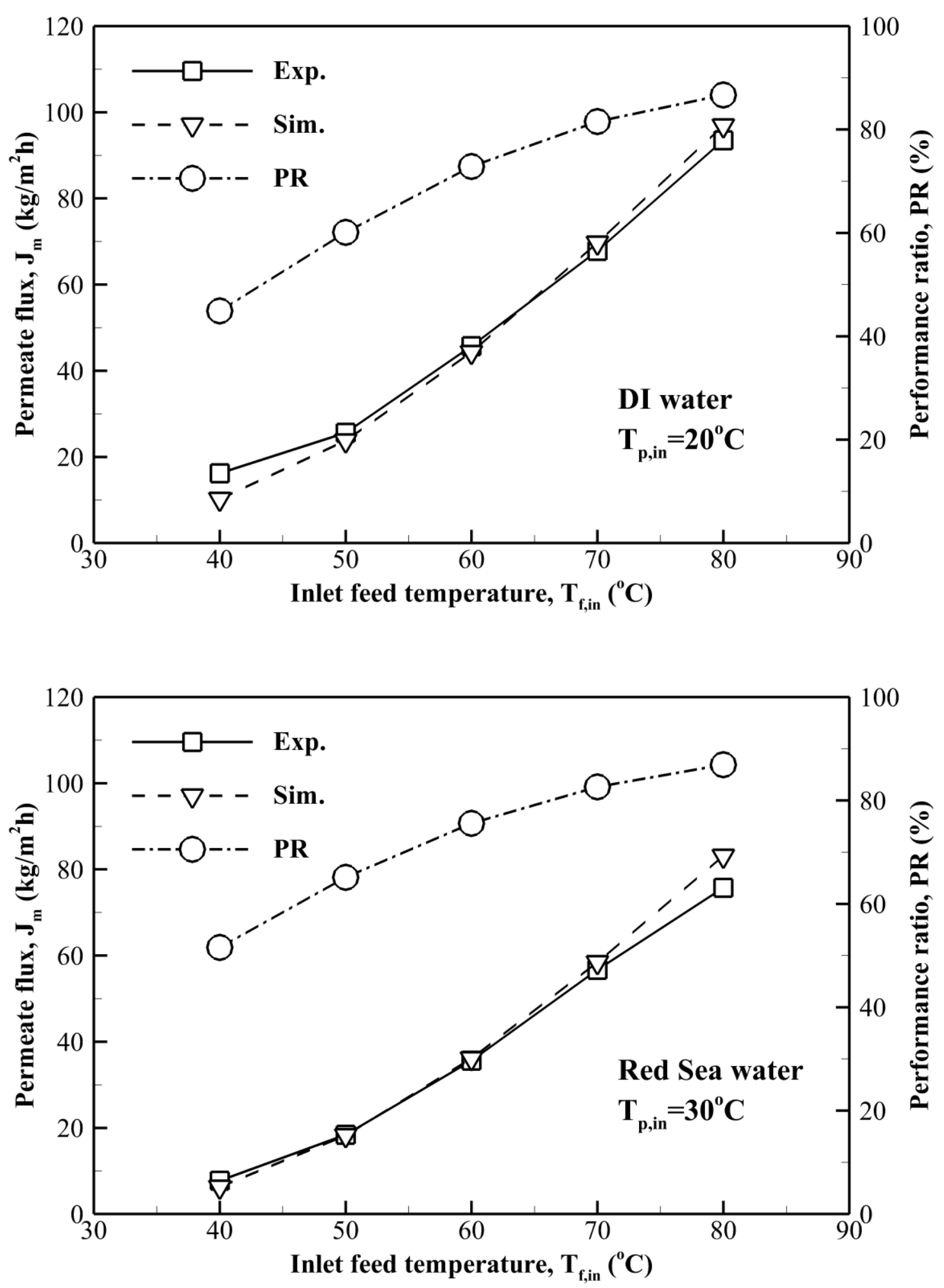


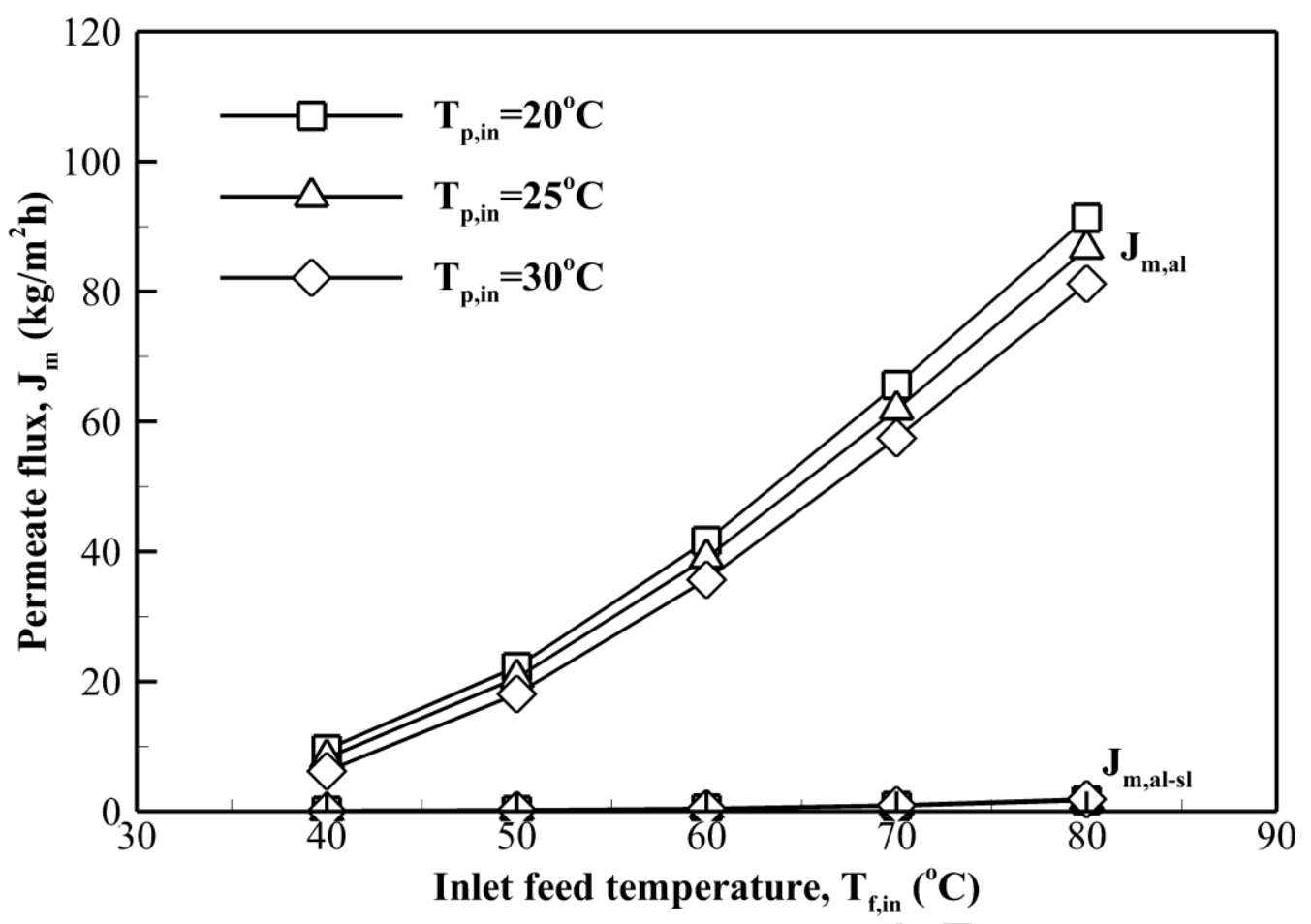




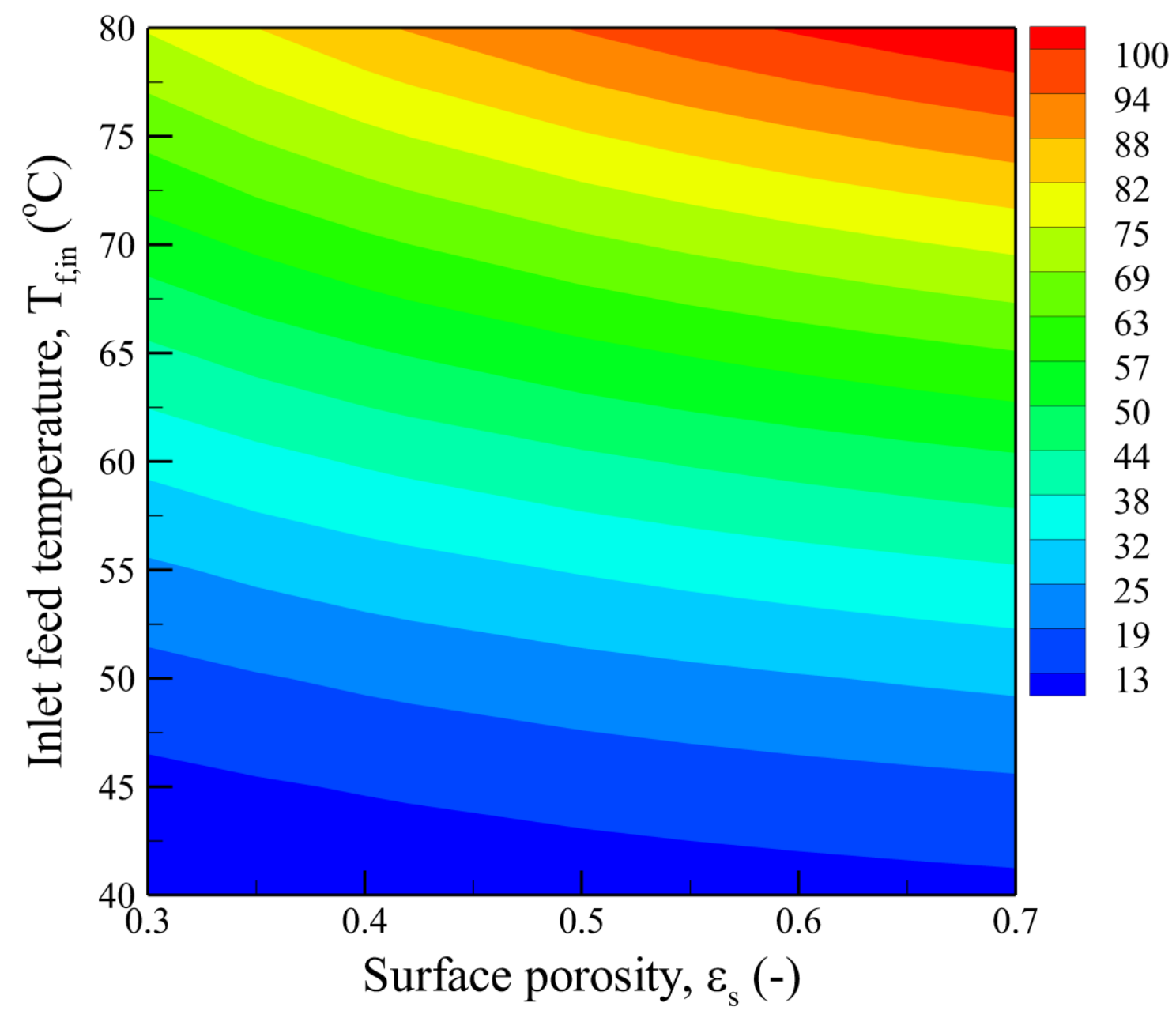




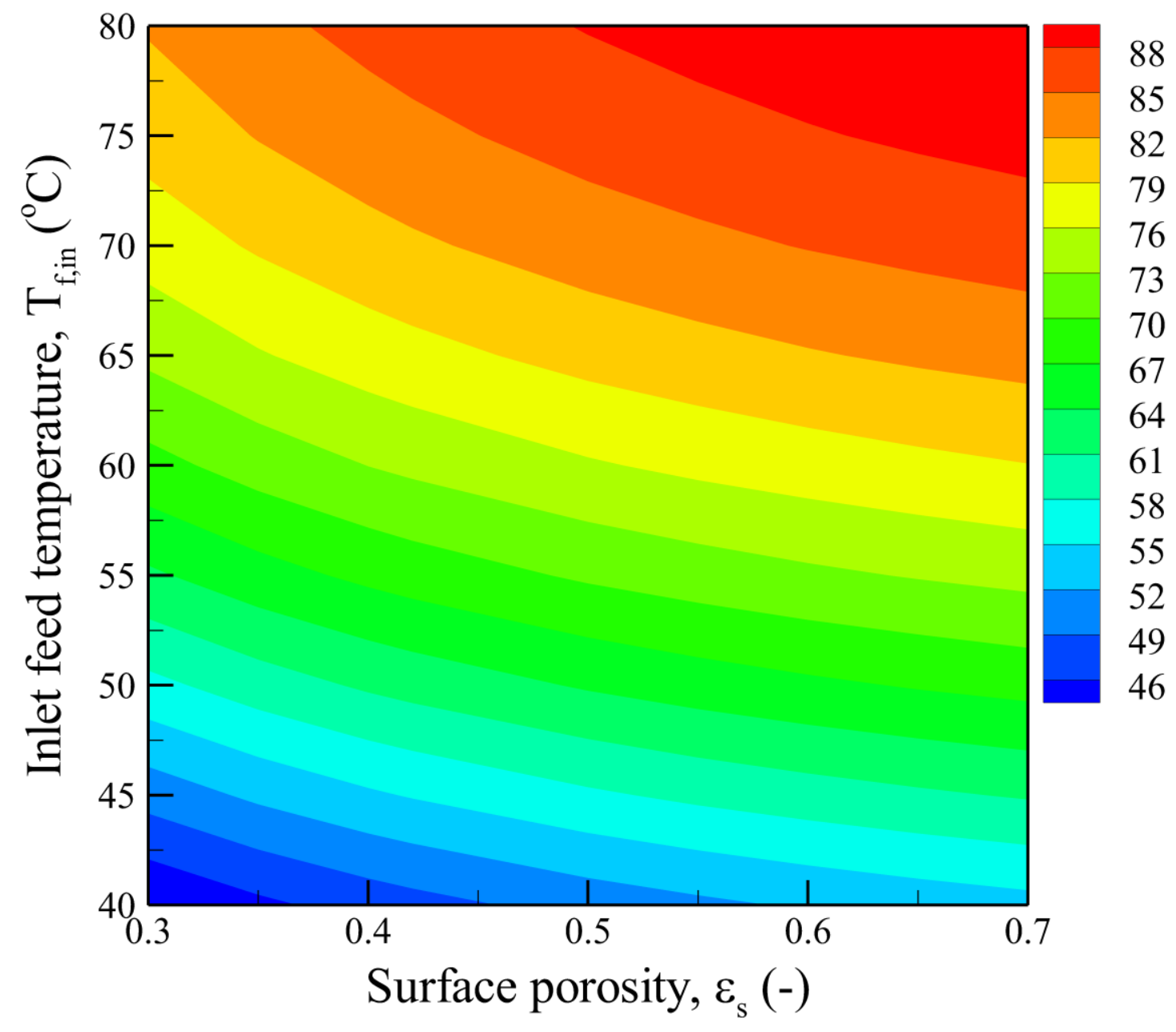




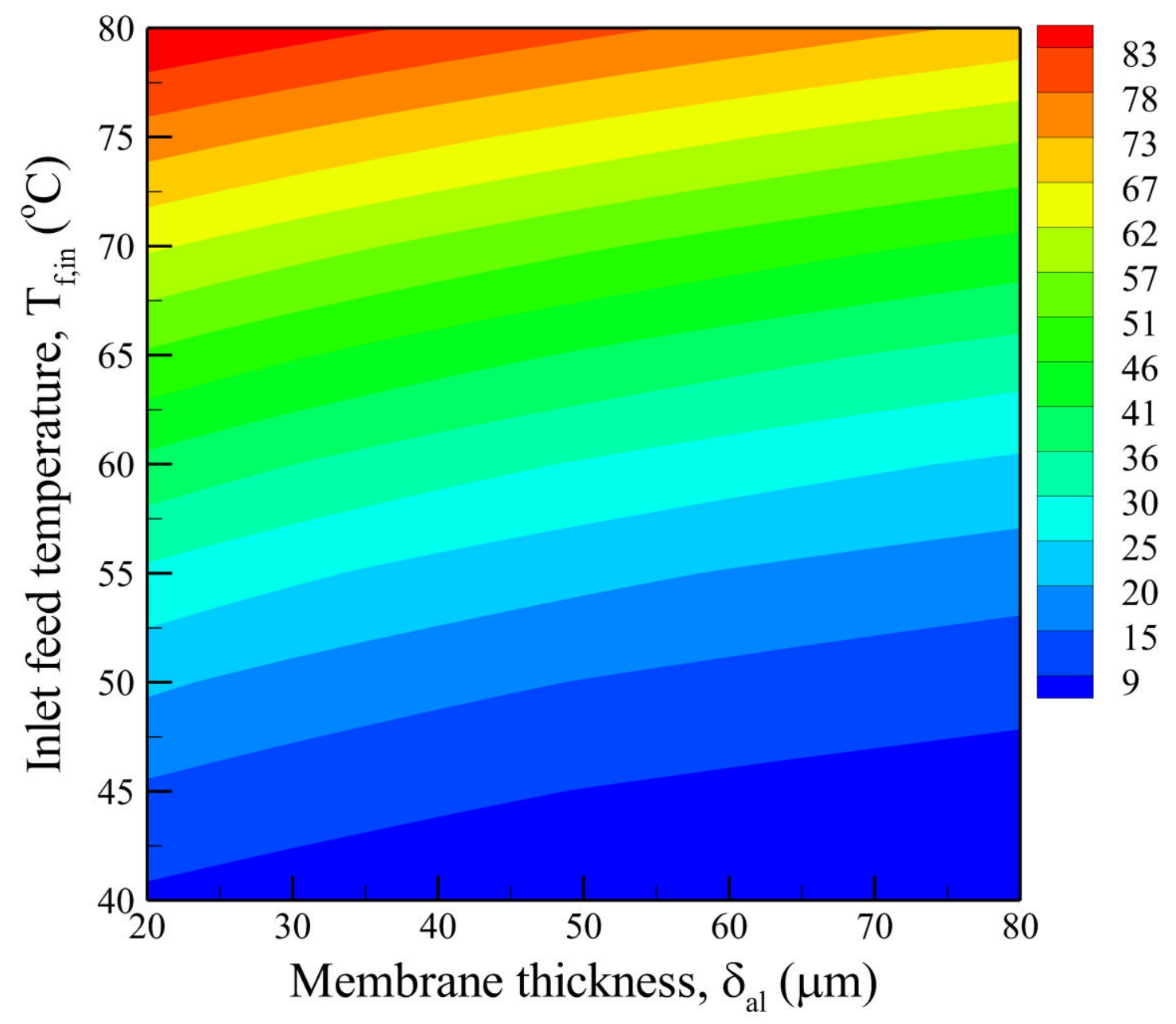




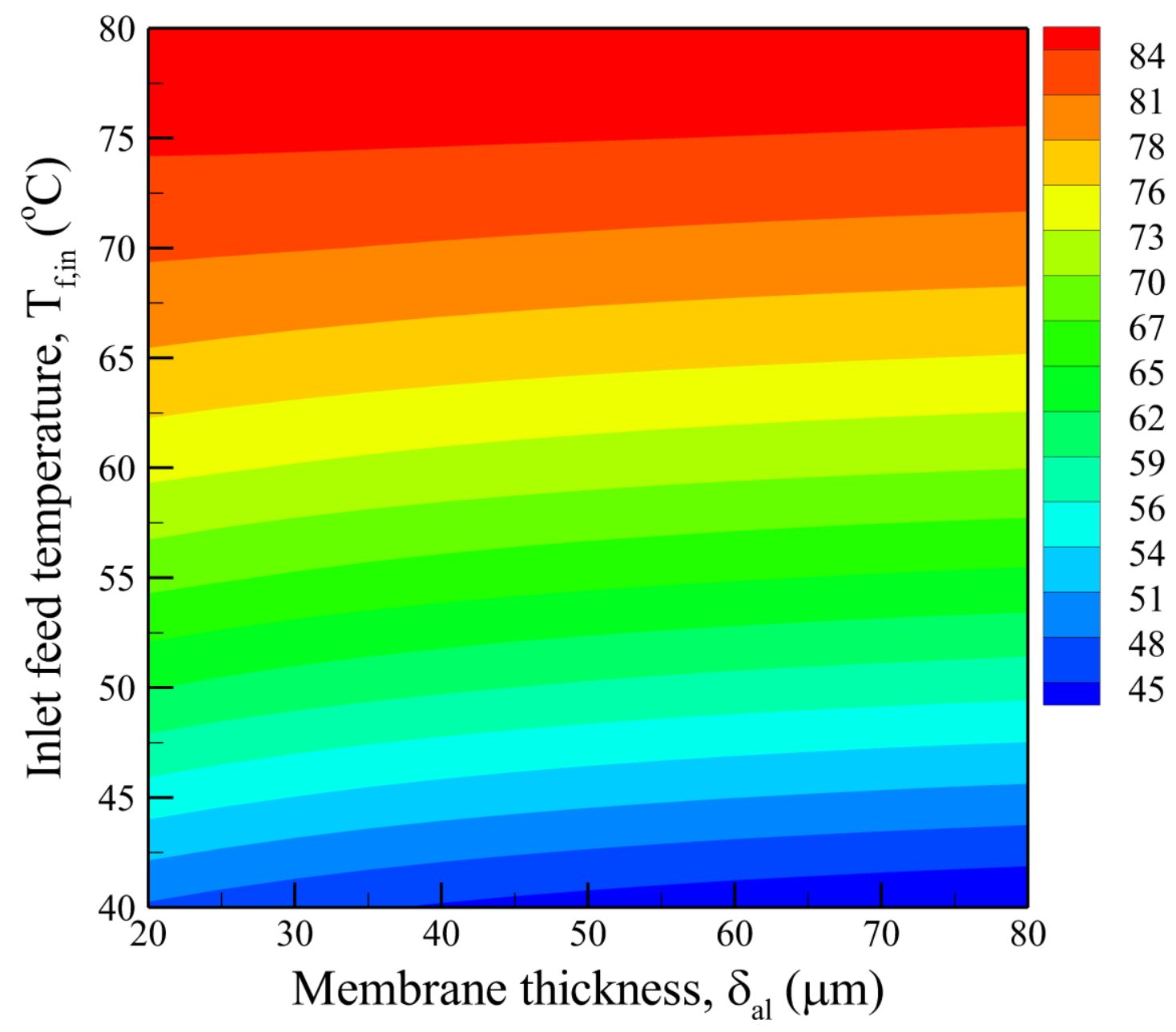




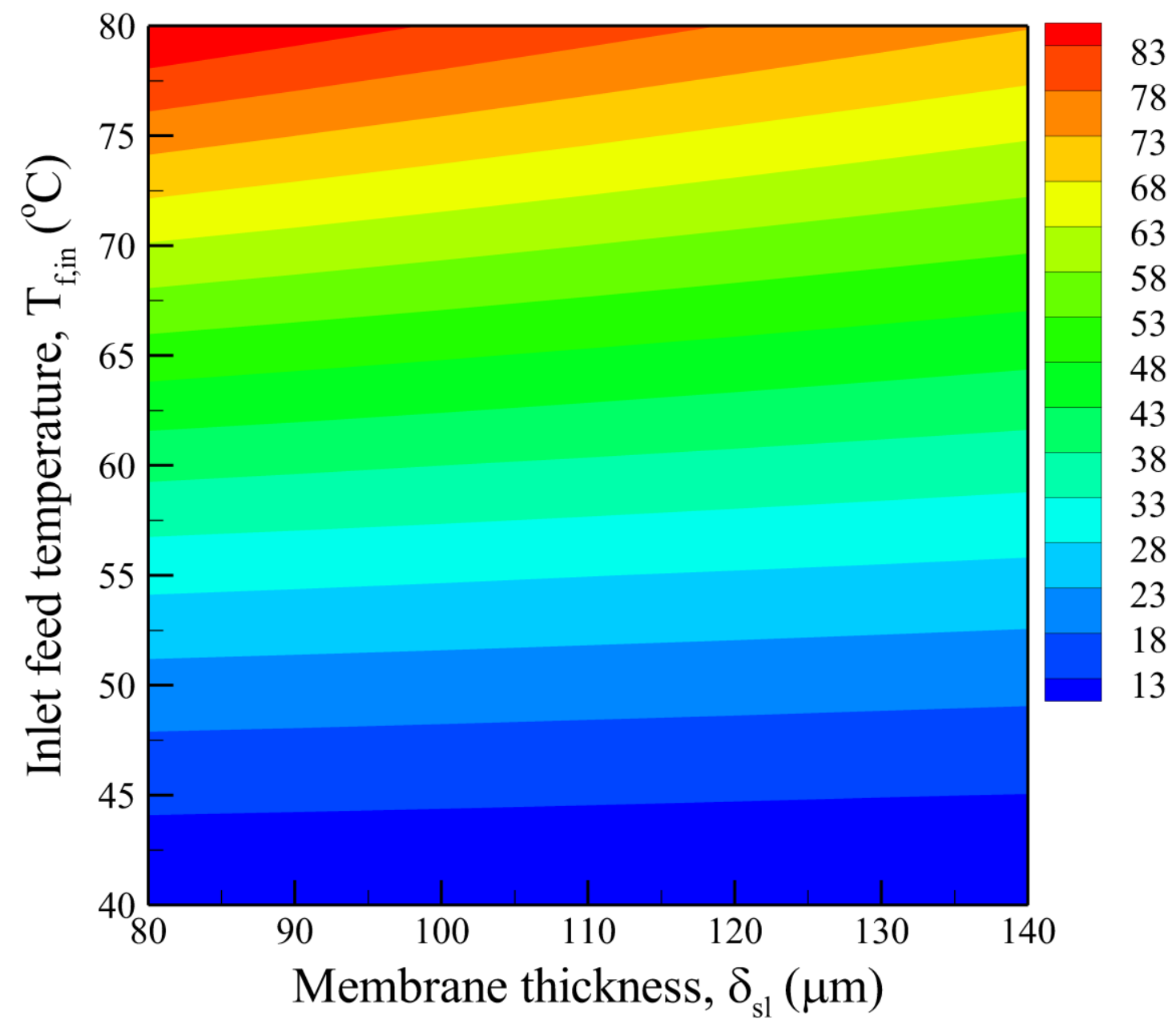




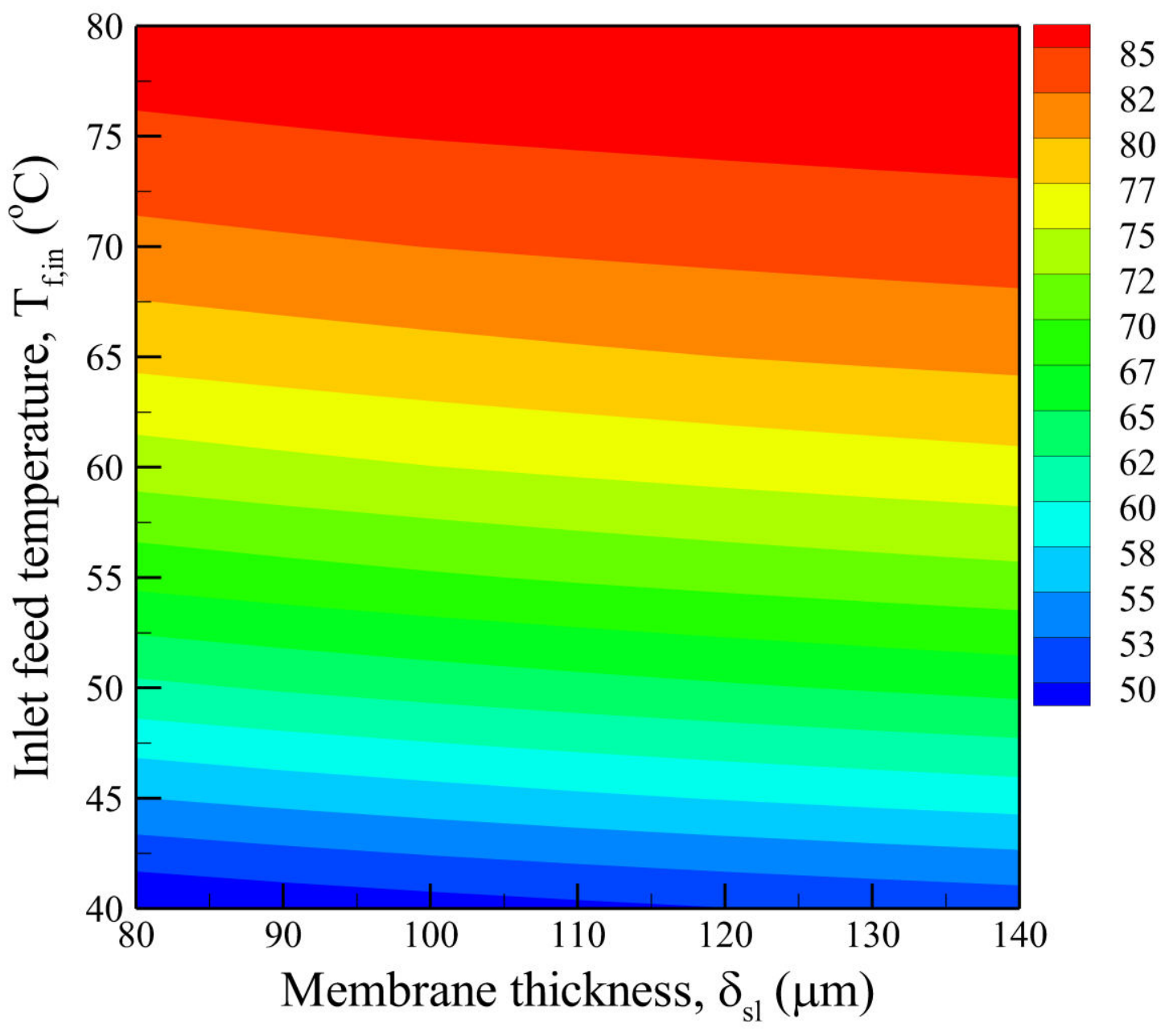

